\title{
Fabrication of PLA-PEG Nanoparticles as Delivery Systems for Improved Stability and Controlled Release of Catechin
}

\author{
Neha Atulkumar Singh, ${ }^{1}$ Abul Kalam Azad Mandal, ${ }^{2}$ and Zaved Ahmed Khan ${ }^{1}$ \\ ${ }^{1}$ Department of Integrative Biology, School of Biosciences and Technology, VIT University, Vellore, Tamil Nadu 632014, India \\ ${ }^{2}$ Department of Biotechnology, School of Biosciences and Technology, VIT University, Vellore, Tamil Nadu 632014, India \\ Correspondence should be addressed to Zaved Ahmed Khan; khan.zaved@gmail.com
}

Received 25 May 2017; Revised 25 July 2017; Accepted 9 August 2017; Published 14 September 2017

Academic Editor: Ilaria Armentano

Copyright (c) 2017 Neha Atulkumar Singh et al. This is an open access article distributed under the Creative Commons Attribution License, which permits unrestricted use, distribution, and reproduction in any medium, provided the original work is properly cited.

\begin{abstract}
The purpose of this study was to develop an oral delivery system for the controlled release of catechin and evaluate the antioxidant potential and stability of catechin loaded PLA/PEG nanoparticles (CATNP). Nanoparticles were synthesized using a double emulsion solvent evaporation method. The fabricated nanoparticles were relatively small with a hydrodynamic diameter of $300 \mathrm{~nm}$ and an encapsulation efficiency of $95 \%$. SEM image analysis showed uniform sized and spherically shaped nanoparticles. In vitro release profiles indicated a slow and sustained release of catechin from the nanoparticle. Stability of the nanoparticle in simulated gastric and intestinal fluids is maintained due to the PEG coating on the nanoparticles, which effectively protected catechin against gastrointestinal enzyme activity. Enhanced inhibition action of free radicals and metal chelation potential was noted when catechin was encapsulated in these polymeric nanoparticles. The reports obtained from this study would provide an opportunity for designing an oral delivery system aimed at inhibiting oxidative stress in the human body.
\end{abstract}

\section{Introduction}

Oxidative degradation is one of the main processes involved in deterioration of foods, which results in reduced nutritive value and product shelf life [1]. This degradation can be triggered by free radicals. Reactive oxygen species including superoxide $\left(\mathrm{O}_{2}{ }^{-}\right)$, hydrogen peroxide $\left(\mathrm{H}_{2} \mathrm{O}_{2}\right)$, and the hydroxyl radical $(\mathrm{OH})$ aggravate oxidative stress by generating new free radicals by converting elements they react with, setting up an autocatalytic chain reaction, which causes cell wall damage through lipid peroxidation. Further activation of these injury mechanisms leads to the development of clinical diseases including heart diseases, diabetes, liver injury, aging, and cancer $[2,3]$.

Transition metals like iron, copper, or cobalt further accelerate this oxidative degradation, as they are ever-present as impurities in food products and the human system. Deposition of these metals damages various organs and disrupts their functioning [4]. Therefore, the perfect balance of free radicals and transition metals is very important for prevention of damage caused by oxidative stress. Nonetheless, some synthetic antioxidants and metal chelators are being used to delay the oxidation process in both food products and the human system. However, they are extremely costly and are associated with various side effects. There is, therefore, a need to develop natural compounds that are capable of preventing oxidative damage with minimum cost and side effects $[2,4]$.

Extensive investigations on catechin and its derivatives have shown that they possess many beneficial properties including radical scavenging, metal chelation, and anticarcinogenic and anti-inflammatory activity. They have also shown generating a significant effect on cell viability and signaling pathways, which makes them a potential therapeutic agent for treatment of cancer, inflammatory diseases, cardiovascular diseases, and neurodegenerative diseases in humans [5-7]. However, the use of these flavonoids is limited due to their poor stability and bioavailability. Factors like $\mathrm{pH}$, temperature, oxygen, light, and gastrointestinal enzymes limit their beneficial properties [8]. Presently, the use of nanotechnology has been particularly useful in the delivery of similar bioactive compounds. Bioactive compound loaded nanoparticle-based approaches have shown great potential in 
protecting and controlling drug release, along with enhanced absorption and bioavailability [3].

Therefore, the aim of the present study was to encapsulate catechin into polymer nanoparticle made of polylactic acid (PLA) and polyethylene glycol (PEG) copolymer and to characterize their stability, physiochemical, antioxidant, and metal chelation properties. The important aspects of this study included the determination of the encapsulation efficiency, in vitro release profiles, and stability studies in simulated gastric and intestinal fluids. The determination of the antioxidant and metal chelation potential of encapsulated catechin over free radicals and transition metals would further our understanding of how they would act in a human system or food products.

This knowledge would consequently help facilitate the designing of an effective delivery system for bioactive compounds with the potential to improve human health and improve shelf life of food products. The protection and sustained release offered by this delivery system could make it suitable for use in pharmaceutical applications and for the development of functional foods. Here, the enhancement of encapsulated catechin's antioxidant and metal chelation potential over free catechin would bring novelty to this study.

\section{Materials and Methods}

2.1. Materials. $(+)$ Catechin (>97\%), poly (D,L-lactic acid) (PLA), polyethylene glycol (PEG), polyvinyl alcohol (PVA), pancreatin $3 \mathrm{x}$, pepsin $1: 1000,3$-(2-pyridyl)-5,6-diphenyl1,2,4-triazine-p, $\mathrm{p}^{\prime}$-disulfonic acid monosodium salt hydrate (Ferrozine), pyrogallol (for synthesis), 2-thiobarbituric acid, 2,2-diphenyl-1-picrylhydrazyl (DPPH), and amyloid beta protein fragments 1-42 were purchased from Sigma Chemical Co. Dichloromethane (DCM) and absolute ethanol (Analytical Grade) were obtained from HiMedia Laboratories, India.

2.2. Preparation of Polymeric Nanoparticles. Double emulsion solvent evaporation method was employed with minor modifications for the synthesis of PLA/PEG nanoparticles [9]. Briefly, PLA and PEG were dissolved in DCM at the ratio of $75: 25$ and six different concentrations of catechin $(1,2,5$, 10,12 , and $15 \mathrm{mg} / \mathrm{ml}$ ) were prepared in $0.1 \%$ PVA solution. Both solutions were mixed and sonicated for $30 \mathrm{~s}$. About $0.7 \%$ of PVA solution was added to this mixture and sonicated for $1 \mathrm{~min}$ to form a water-oil-water emulsion. After evaporation of the organic solvent at room temperature, nanoparticles were recovered by centrifugation at $12,000 \mathrm{~g}$ for $20 \mathrm{~min}$ at $4^{\circ} \mathrm{C}$. The nanoparticles were washed twice with water to remove any remaining surfactants.

2.3. Characterization. HR-SEM (FEI Quanta FEG 200, HighResolution Scanning Electron Microscope) was used to study the surface morphology of the nanoparticles $(10 \mathrm{mg} / \mathrm{ml})$. Hydrodynamic diameter and the zeta potential of CATNP $(10 \mathrm{mg} / \mathrm{ml})$ were determined using dynamic light scattering (Zetasizer with Ver. 6.12 software) [10]. To better understand the structure of free catechin $(10 \mathrm{mg} / \mathrm{ml})$, CATNP $(10 \mathrm{mg} / \mathrm{ml})$, and unloaded nanoparticles, Fourier transform infrared spectra (FT-IR) (FT-IR spectroscopy, Siemens 578564) and $\mathrm{X}$-ray diffraction (XRD) patterns (X-ray diffraction instrument, D8 Advance, BRUKER, Germany) were recorded.

2.3.1. Determination of Catechin Encapsulation Efficiency. Vanillin assay was used to determine the catechin encapsulation efficiency of six concentrations of CATNP, namely, 1 , $2,5,10,12$, and $15 \mathrm{mg} / \mathrm{ml}$. The measurements were taken at $500 \mathrm{~nm}$ with a UV-VIS spectrophotometer $[11,12]$.

$$
\mathrm{EE} \%=\frac{\text { Amount of catechin entrapped }}{\text { Total amount of catechin }} \cdot 100 \text {. }
$$

All measurements were performed in triplicate.

2.3.2. In Vitro Catechin Release from Nanoparticles. Dialysis bag diffusion technique with minor modifications was employed for in vitro catechin release studies [13]. The study was performed for six concentrations of CATNP, namely, 1 , $2,5,10,12$, and $15 \mathrm{mg} / \mathrm{ml}$. Briefly, the catechin was loaded in the dialysis bag and immersed in phosphate buffer solution (PBS) of $\mathrm{pH}$ 7.4. This system was stirred at $200 \mathrm{rpm}$ at room temperature and samples were collected at specific time intervals. The study was carried out for over $40 \mathrm{~h}$ and samples were analyzed with a UV-VIS spectrophotometer.

2.3.3. Mathematical Modeling of Release Kinetics. The release kinetics of CATNP $(10 \mathrm{mg} / \mathrm{ml})$ was studied to determine the mechanism of catechin release. The in vitro release data for CATNP $(10 \mathrm{mg} / \mathrm{ml})$ under physiological conditions was fitted into various mathematical models including, zero-order, first-order, Higuchi, Hixson-Crowell, and Korsmeyer-Peppas models [14] (Table 1). To determine the best fit for each model value of the correlation coefficient $\left(R^{2}\right)$ was used as an indicator. Based on the release exponent $(n)$ value, the release mechanism of the catechin was determined [15] (Table 2).

2.3.4. Catechin Stability. Simulated gastric fluid (SGF) and simulated intestinal fluid (SIF) were used to analyze the stability of CATNP $(10 \mathrm{mg} / \mathrm{ml})$. SGF and SIF were prepared with the addition of enzymes, pepsin and pancreatin, in SGF and SIF, respectively [16]. The tubes were incubated in an orbital shaker at $37^{\circ} \mathrm{C}$ with 130 rotations per minute (rpm). They were incubated for specific time intervals such as $5 \mathrm{~min}, 10 \mathrm{~min}, 15 \mathrm{~min}, 30 \mathrm{~min}, 1 \mathrm{~h}, 2 \mathrm{~h}, 3 \mathrm{~h}$, and $6 \mathrm{~h}$. After the specific time interval the samples were removed and the suspension was centrifuged at $8000 \mathrm{rpm}$ for $10 \mathrm{~min}$. The supernatant was collected and analyzed. The absorbance of samples collected at specific time intervals was analyzed using a UV-VIS spectrophotometer.

2.4. Antioxidant Assays. Antioxidant assays were carried out with 2 different groups, namely, free catechin $(10 \mathrm{mg} / \mathrm{ml})$ and CATNP $(10 \mathrm{mg} / \mathrm{ml})$.

2.4.1. Superoxide Anion Scavenging. The free radical scavenging activity of the samples was measured in vitro by superoxide anion scavenging assay [17]. Briefly, samples were dissolved in $75 \mathrm{mM}$ Tris- $\mathrm{HCl}$ of $\mathrm{pH} 8.2$ and incubated at $4^{\circ} \mathrm{C}$ 
TABLE 1: Equations and parameters of mathematical models.

\begin{tabular}{|c|c|c|}
\hline Model & Equation & Parameter definition \\
\hline Zero order & $C=k_{o} t$ & $\begin{array}{c}C: \text { concentration of drug } \\
k_{o}: \text { zero-order constant } \\
t: \text { time }\end{array}$ \\
\hline First order & $\begin{array}{c}\log C_{o}-\log C_{t}= \\
\frac{k_{1} t}{2.303}\end{array}$ & $\begin{array}{c}C_{o}: \text { initial concentration } \\
C_{t}: \text { concentration at time } t \\
k_{1}: \text { first-order constant } \\
t \text { : time }\end{array}$ \\
\hline $\begin{array}{l}\text { Higuchi } \\
\text { model }\end{array}$ & $Q=k_{\mathrm{H}} t^{1 / 2}$ & $\begin{array}{c}\text { Q: amount of drug released in } \\
\text { time } t \\
k_{\mathrm{H}}: \text { Higuchi constant } \\
t \text { : time }\end{array}$ \\
\hline $\begin{array}{l}\text { Hixson- } \\
\text { Crowell } \\
\text { model }\end{array}$ & $\begin{array}{c}Q_{o}^{1 / 3}-Q_{t}^{1 / 3}= \\
k_{\mathrm{HC}} t^{t}\end{array}$ & $\begin{array}{c}Q_{o}: \text { initial amount of drug } \\
Q_{t}: \text { remaining amount of drug } \\
\text { at time } t \\
k_{\mathrm{HC}} \text { : Hixson-Crowell constant } \\
t \text { : time }\end{array}$ \\
\hline $\begin{array}{l}\text { Korsmeyer- } \\
\text { Peppas } \\
\text { model }\end{array}$ & $M_{t}-M_{\alpha}=k t^{n}$ & $\begin{array}{c}M_{t}-M_{\alpha}: \text { fraction of drug } \\
\text { released at time } t \\
k: \text { Korsmeyer-Peppas constant } \\
t \text { : time } \\
n: \text { release exponent }\end{array}$ \\
\hline
\end{tabular}

TABLE 2: Interpretation of diffusion release mechanisms.

\begin{tabular}{lc}
\hline Release exponent $(n)$ & Drug transport mechanism \\
\hline$n<0.5$ & Fickian diffusion \\
$0.45<n<0.89$ & Non-Fickian transport \\
0.89 & Case II transport \\
$0.89<n$ & Super case II transport \\
\hline
\end{tabular}

for $1 \mathrm{~h}$. Then $30 \mathrm{mM}$ EDTA and $2 \mathrm{mM}$ pyrogallol were added and the absorbance was taken at $470 \mathrm{~nm}$ using a UV-VIS spectrophotometer.

$$
\begin{aligned}
X & =\text { Absorbance of }(0 \mathrm{~min}-1 \mathrm{~min}), \\
Y & =\frac{\text { Absorbance of } 2 \mathrm{~min}}{2}, \\
Z & =\frac{\text { Absorbance of } 3 \mathrm{~min}}{3}, \\
B & =\frac{X+Y+Z}{3}, \\
C & (1 \% \text { of antioxidation) } \\
& =\frac{B \text { (Absorbance of control) }}{A \text {. }} \cdot 100,
\end{aligned}
$$

Inhibition $\%=\frac{C}{50} \cdot \frac{\text { Total volume of solution }}{0.5} \cdot \frac{1}{0.5}$.
2.4.2. Lipid Peroxidation. The free radical scavenging activity of the samples was also measured in vitro by lipid peroxidation assay $[18,19]$. Briefly, the samples were dissolved in $0.1 \mathrm{M}$ Tris- $\mathrm{HCl}$ buffer of $\mathrm{pH} 7.4$ and incubated at $37^{\circ} \mathrm{C}$ for $2 \mathrm{~h}$ with constant shaking. About $10 \% \mathrm{w} / \mathrm{v}$ TCA was added and the mixture was centrifuged at $5000 \mathrm{rpm}$ for $10 \mathrm{~min}$. An equal amount of $0.67 \% \mathrm{w} / \mathrm{v}$ TBA was added to the supernatant and incubated for $1 \mathrm{~h}$ in boiling water $\left(100^{\circ} \mathrm{C}\right)$. The mixture was allowed to cool down and diluted in double distilled water, which was followed by centrifugation at $5000 \mathrm{rpm}$ for $10 \mathrm{~min}$. The absorbance of the upper organic layer was measured at $532 \mathrm{~nm}$ using a UV-VIS spectrophotometer.

$$
\text { Inhibition } \%=\frac{\text { Absorbance }}{0.015} \cdot 1 \cdot \frac{1}{0.2} \text {. }
$$

2.4.3. DPPH Assay. The free radical scavenging activity of the samples was also measured in vitro by DPPH assay [20]. Briefly, sample concentrations ranging between 10 and $500 \mu \mathrm{g} / \mathrm{ml}$ were prepared using appropriate solvents. About $0.1 \mathrm{M}$ DPPH was prepared and added to the samples, which were then incubated in dark at room temperature for $30 \mathrm{~min}$. The absorbance was measured at $517 \mathrm{~nm}$ using a UV-VIS spectrophotometer.

$$
\begin{aligned}
& \text { Scavenging activity } \% \\
& \qquad=\frac{\text { Absorbance (control }- \text { sample) }}{\text { Absorbance of control }} \cdot 100 .
\end{aligned}
$$

2.5. Metal Chelating Activity Assay. The chelating activity of $\mathrm{Fe}^{2+}$ was measured by previously established protocols [2, 21]. Briefly, samples were dissolved in deionized water to which $2 \mathrm{mM} \mathrm{FeCl}_{2}$ was added. This mixture was allowed to stand for $30 \mathrm{~s}$. To this $5 \mathrm{mM}$ Ferrozine was added and incubated at room temperature for $10 \mathrm{~min}$. The absorbance was measured at $562 \mathrm{~nm}$ using a UV-VIS spectrophotometer.

$$
\begin{aligned}
\text { Chelation rate } \%= & \frac{\text { Absorbance }(\text { control }- \text { sample })}{\text { Absorbance of control }} \\
& \cdot 100 .
\end{aligned}
$$

\section{Results}

3.1. Physiochemical Properties of Nanoparticles. Characterization was carried out for CATNP of $10 \mathrm{mg} / \mathrm{ml}$ concentration.

3.1.1. Morphological and Electrical Properties. The surface morphology of CATNP was analyzed using HR-SEM (Figure 1). It confirmed the formation of nanoparticles with a uniform, spherical to slightly ellipsoid shape, with a smooth surface. The average particle sizes were $300 \mathrm{~nm}$. The hydrodynamic diameter of CATNP $(10 \mathrm{mg} / \mathrm{ml})$ was $342.1 \mathrm{~nm}$ (Figure 2(a)), while the zeta potential was $-22.1 \mathrm{mV}$ (Figure 2(b)).

3.1.2. Nanoparticle Matrix Properties. The XRD patterns were measured for free catechin $(10 \mathrm{mg} / \mathrm{ml})$, CATNP $(10 \mathrm{mg} / \mathrm{ml})$, and unloaded nanoparticles. The XRD patterns of CATNP 


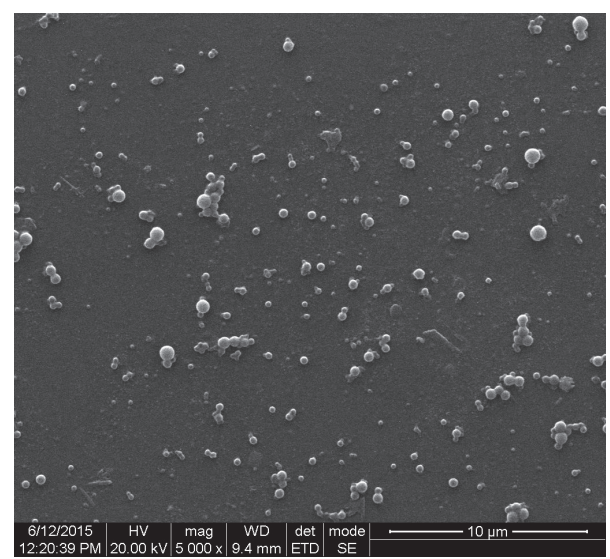

FIGURE 1: Surface morphology of CATNP $(10 \mathrm{mg} / \mathrm{ml})$.

were similar to the unloaded nanoparticles rather than the free form of catechin (Figure 3(a)). FT-IR analysis was also carried out for the same. Here CATNP represented the characteristic peaks of the free catechin, $\mathrm{C}=\mathrm{C}$ stretch in the aromatic ring (1600 and $\left.1475 \mathrm{~cm}^{-1}\right)$ and $\mathrm{OH}$ stretch $\left(3600-3200 \mathrm{~cm}^{-1}\right)$ and the unloaded nanoparticles, $-\mathrm{CH} 3$ stretching $\left(2850-3000 \mathrm{~cm}^{-1}\right), \mathrm{C}=\mathrm{O}$ stretch $\left(1700-1800 \mathrm{~cm}^{-1}\right)$, and the C-O stretching of the oxygen ring $\left(1050-1250 \mathrm{~cm}^{-1}\right)$ (Figures 3(b), 3(c), and 3(d)).

3.1.3. Encapsulation Properties. The encapsulation efficiency was measured and is presented in Table 3. Maximum encapsulation efficiency was found to be $95.50 \%$ for $10 \mathrm{mg} / \mathrm{ml} \mathrm{con-}$ centration of CATNP. The other concentrations of CATNP had encapsulation efficiencies ranging from 81.50 to $94.00 \%$.

3.1.4. In Vitro Release Assay. The in vitro release profiles of all concentrations of CATNP are presented in Figure 4(a). CATNP at high concentrations displayed a sudden burst in catechin release. In the case of $10 \mathrm{mg} / \mathrm{ml}$ concentration of CATNP this burst was noted at the 7 th $\mathrm{h}$ with the release of $45.58 \%$ of catechin from the nanoparticle. After the initial burst, sustained release of the catechin from the CATNP was noted and about $75.62 \%$ of the total catechin was released in $40 \mathrm{~h}$.

3.1.5. Mathematical Modeling of Release Kinetics. In vitro release profiles were fitted into various mathematical models to determine the release kinetics (Table 4) and release mechanism of catechin (Table 5). Based on the correlation coefficient $\left(R^{2}\right)$ and release kinetic constant values, CATNP $(10 \mathrm{mg} / \mathrm{ml})$ formulation showed good correlation with Hixson-Crowell kinetics. The value of the release exponent $(n)$ showed that the release mechanism followed was Fickian diffusion.

3.1.6. Catechin Stability in Simulated Gastric and Intestinal Fluids. SGF and SIF were used to evaluate the stability of CATNP $(10 \mathrm{mg} / \mathrm{ml})$ under physiological conditions. The percentage of catechin remaining at the end of $3 \mathrm{~h}$ in SGF
TABLE 3: Encapsulation efficiency of different concentration of CATNP.

\begin{tabular}{lc}
\hline Concentration $(\mathrm{mg} / \mathrm{ml})$ & CATNP $^{\mathrm{a}}(\%)$ \\
\hline 1 & $81.50 \pm 1.80$ \\
2 & $82.75 \pm 1.29$ \\
5 & $91.50 \pm 1.44$ \\
10 & $95.50 \pm 1.44$ \\
12 & $94.00 \pm 1.73$ \\
15 & $93.00 \pm 1.73$ \\
\hline${ }^{a}$ CATNP. catechin encapsulated polymeric nanoparticles.
\end{tabular}

${ }^{a}$ CATNP: catechin encapsulated polymeric nanoparticles.

TABLE 4: Release kinetics of catechin from nanocatechin $(10 \mathrm{mg} / \mathrm{ml})$ formulation.

\begin{tabular}{lcc}
\hline Kinetic model & $\begin{array}{c}\text { Correlation } \\
\text { coefficient }\left(R^{2}\right)\end{array}$ & $\begin{array}{c}\text { Kinetic constant } \\
(k)\end{array}$ \\
\hline Zero order & 0.9649 & $k_{o}=0.0225$ \\
First order & 0.9637 & $k_{1}=0.0014$ \\
Higuchi model & 0.9649 & $k_{\mathrm{H}}=1.1022$ \\
Hixson-Crowell model & 0.9701 & $k_{\mathrm{HC}}=0.0035$ \\
\hline
\end{tabular}

TABLE 5: Release mechanism of catechin from nanocatechin $(10 \mathrm{mg} / \mathrm{ml})$ formulation.

\begin{tabular}{lc}
\hline Kinetic model & Release exponent $(n)$ \\
\hline Korsmeyer-Peppas model & $n=0.0828$ \\
& Fickian diffusion \\
\hline
\end{tabular}

was $73.33 \%$, while at the end of $6 \mathrm{~h}$ in SIF it was $63.75 \%$ (Figure 4(b)).

3.2. Antioxidant Capacity. Figures 5(a), 5(b), and 5(c) display the free radical scavenging ability for free catechin $(10 \mathrm{mg} / \mathrm{ml})$ and CATNP $(10 \mathrm{mg} / \mathrm{ml})$ measured over $40 \mathrm{~h}$. Highest scavenging activity was noted at the initial burst hour (i.e., 7th hour), where CATNP showed DPPH free radical scavenging ability of around $93 \%$ with superoxide anion scavenging and lipid peroxidation activity of around $12 \%$ and $57 \%$, respectively. A 1.64-, 1.65-, and 1.57-fold increase in activity for $\mathrm{DPPH}$, lipid peroxidation, and superoxide scavenging assays was seen in CATNP.

3.3. Metal Chelating Activity Assay. Figure 5(d) displays the metal chelation ability for free catechin and CATNP. This activity was measured over $40 \mathrm{~h}$. Highest chelation activity of $83 \%$ was noted at the initial burst hour. A 1.51 -fold boost in activity was noted in the metal chelation rate of CATNP.

\section{Discussion}

4.1. Synthesis of Catechin Loaded PLA/PEG Nanoparticles. Double solvent evaporation method was employed for the encapsulation of catechin into PLA/PEG nanoparticles. Sonication at low temperatures was carried out in order to synthesize emulsions with enhanced antioxidant and metal chelation potential [22]. Here, PVA was used as a surfactant 


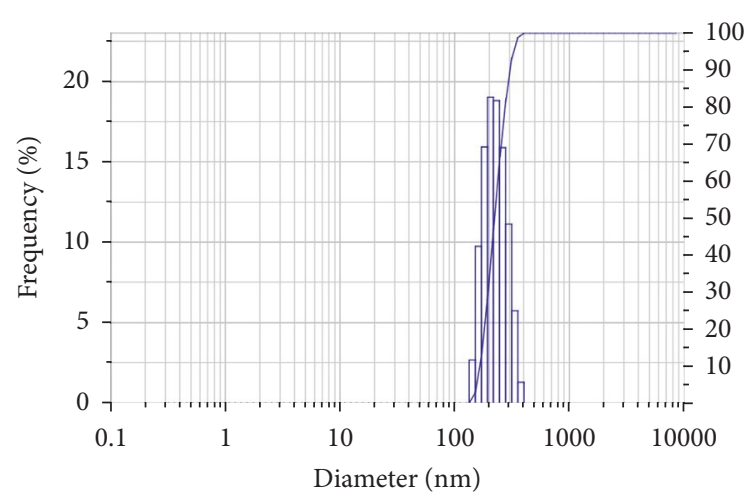

(a)

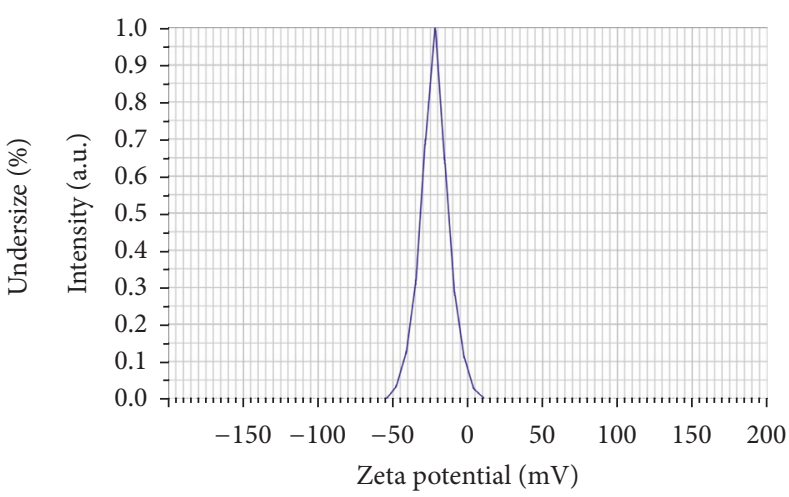

(b)

Figure 2: (a) Particle size and (b) zeta potential of CATNP $(10 \mathrm{mg} / \mathrm{ml})$.

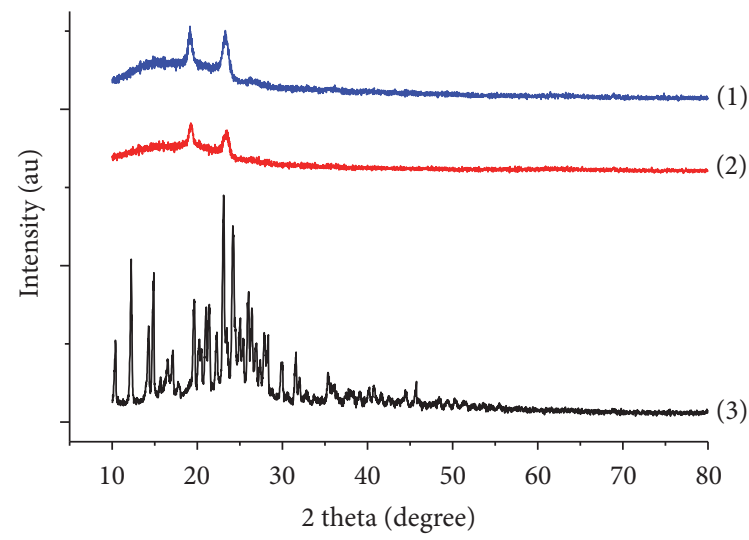

(a)

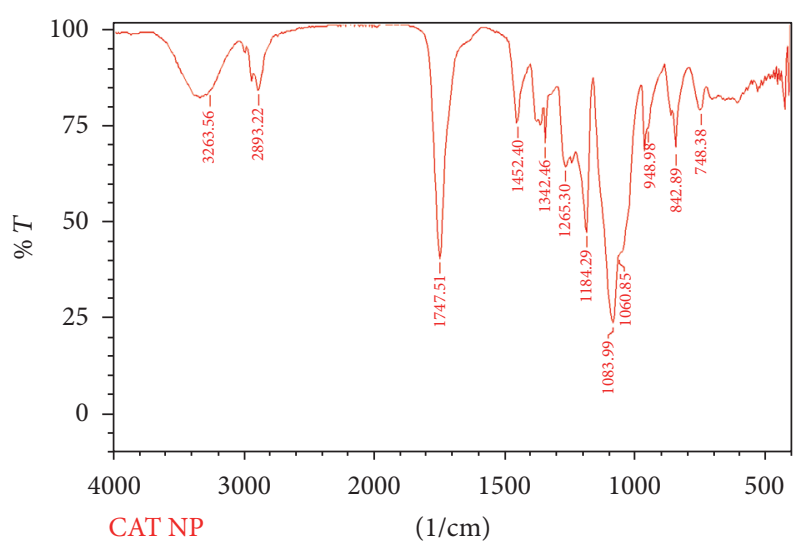

(c)

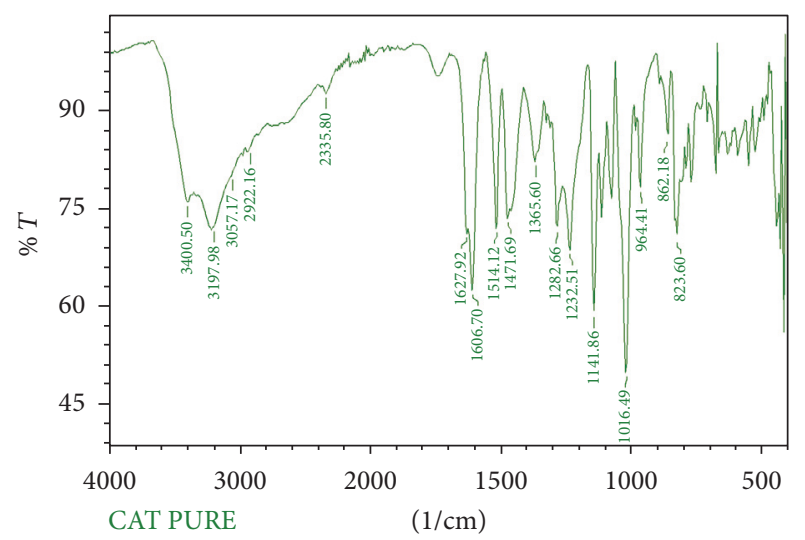

(b)

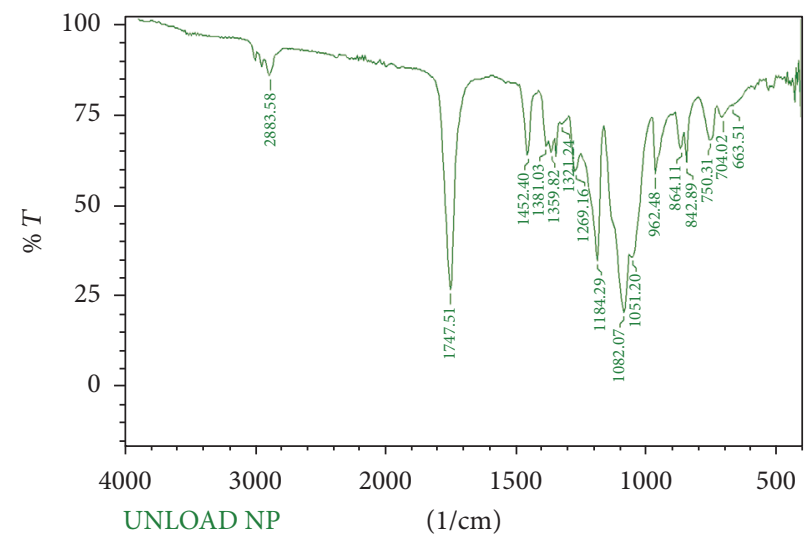

(d)

FIGURE 3: (a) XRD spectra of (1) unloaded nanoparticle, (2) CATNP (10 mg/ml), and (3) free catechin (10 mg/ml). FT-IR spectra of (b) free catechin $(10 \mathrm{mg} / \mathrm{ml}),(\mathrm{c})$ CATNP $(10 \mathrm{mg} / \mathrm{ml})$, and (d) unloaded nanoparticle.

to maintain the stability of the emulsion during solvent evaporation. This single volume shrinkage of the emulsion droplets led to the generation of nanoparticles [23, 24]. Additionally, these nanoparticles were coated with PEG to enhance the drug's bioavailability and stability [25]. Our studies suggested that the PEG coating on the nanoparticles protected approximately $60 \%$ of catechin against gastrointestinal enzyme activity.
4.2. Characterization of Catechin Loaded PLA/PEG Nanoparticles. Physiochemical properties hold much importance in determining functional performance [26], toxicity, drug loading, targeting ability, biological activity, release, and stability [27]. CATNP synthesized in this study had particle sizes ranging from $200 \mathrm{~nm}$ to $400 \mathrm{~nm}$. They also had strong electrostatic repulsion forces which prevented their aggregation as their zeta potentials were $-22.1 \mathrm{mV}$ [28]. 


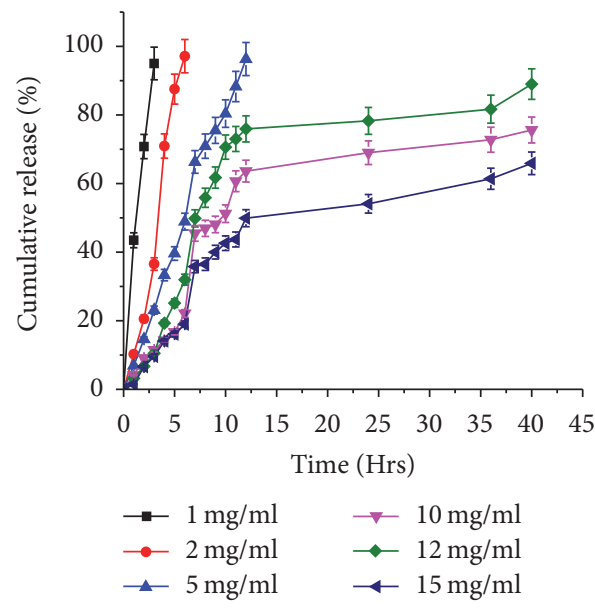

(a)

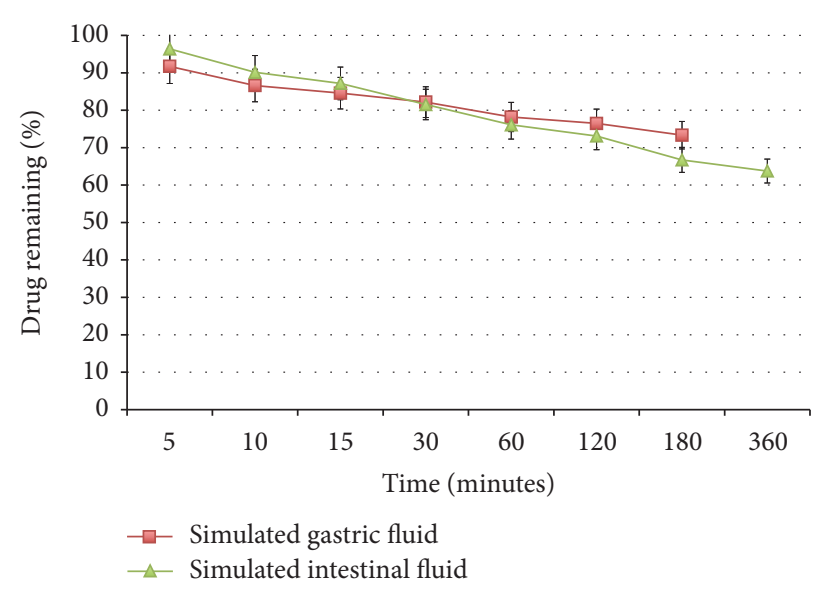

(b)

FIGURE 4: In vitro release study (a) of all concentrations for CATNP under physiological conditions and (b) of $10 \mathrm{mg} / \mathrm{ml}$ concentration of CATNP in simulated gastric fluid and simulated intestinal fluid.

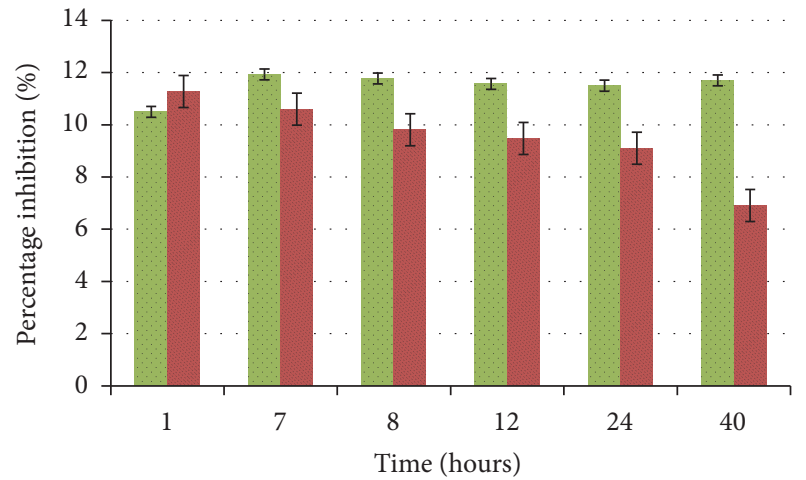

CATNP

Free catechin

(a)

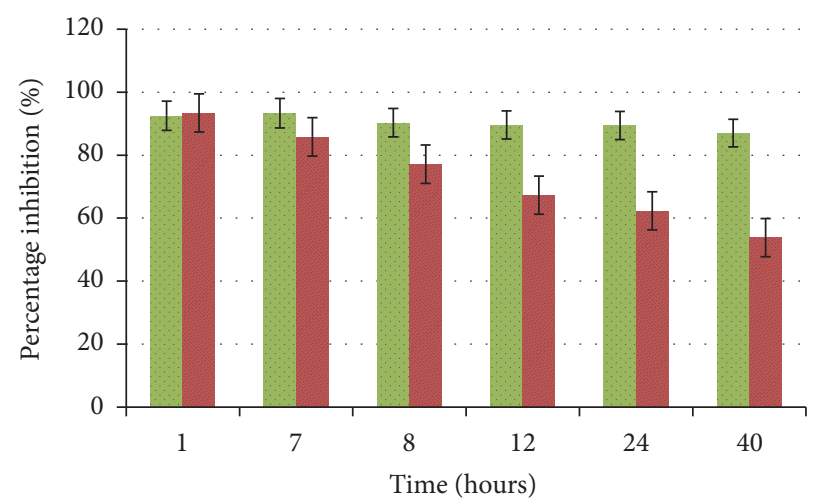

CATNP

Free catechin

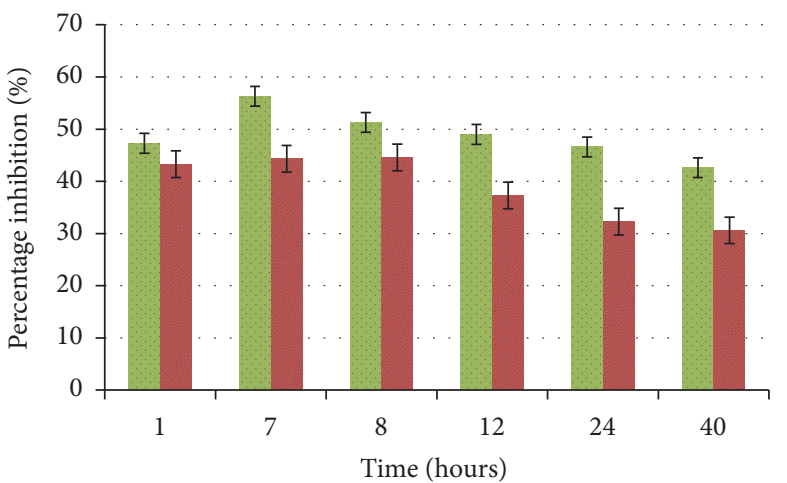

CATNP

- Free catechin

(b)

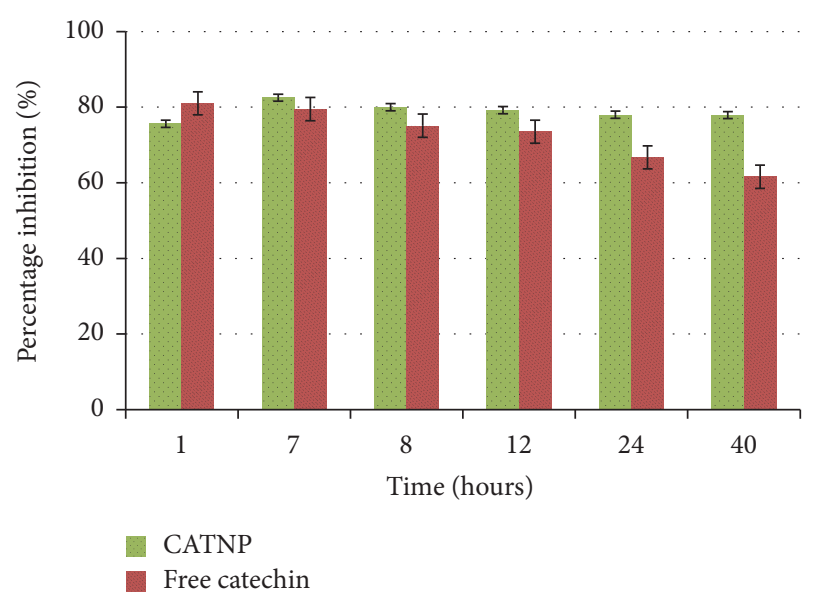

(d)

FIGURE 5: Antioxidant and metal chelation assays of free catechin $(10 \mathrm{mg} / \mathrm{ml})$ and CATNP $(10 \mathrm{mg} / \mathrm{ml})$. (a) Superoxide scavenging activity, (b) lipid peroxidation, (c) DPPH activity, and (d) metal chelation potential. 
XRD and FT-IR spectra analysis attested to the successful encapsulation of catechin into PLA/PEG nanoparticles. Based on previous XRD studies we know that free catechin is crystalline in nature $[29,30]$ and unloaded nanoparticles are amorphous in nature [8]. The XRD spectra for CATNP had peaks that closely resembled those generated by the unloaded nanoparticles rather than its free form. Similarly the FT-IR spectra analysis showed characteristic peaks for free catechin, $\mathrm{C}=\mathrm{C}$ stretch in the aromatic ring (1600 and $1475 \mathrm{~cm}^{-1}$ ) and $\mathrm{OH}$ stretch $\left(3600-3200 \mathrm{~cm}^{-1}\right)$ and unloaded nanoparticles, $-\mathrm{CH} 3$ stretching $\left(2850-3000 \mathrm{~cm}^{-1}\right)$, $\mathrm{C}=\mathrm{O}$ stretch $\left(1700-1800 \mathrm{~cm}^{-1}\right)$, and the $\mathrm{C}-\mathrm{O}$ stretching of the oxygen ring $\left(1050-1250 \mathrm{~cm}^{-1}\right)$ which were in support with the previous literature [31-33]. But the spectra analysis for CATNP showed characteristic peaks from both free catechin and unloaded nanoparticles with only a slight shift in space, thus attesting to the positive encapsulation of catechin into PLA/PEG nanoparticles. Furthermore, the encapsulation efficiency of catechin into PLA/PEG nanoparticles holds much importance and is mainly dependent on drug solubility, polymer composition, and functional groups [34, 35]. For CATNP the encapsulation efficiency was approximately $95 \%$, which suggested that very little catechin was partitioned into the aqueous phase during nanoparticle synthesis.

\subsection{Release Rate and Antioxidant Potential of Catechin Loaded} PLA/PEG Nanoparticles. In vitro catechin release profiles were generated for different concentration of CATNP under physiological conditions. It was noted that catechin release from CATNP was faster for the first few hours followed by a slow and sustained release in the later hours. In support with previous studies, we observed an initial catechin burst at the 7 th $\mathrm{h}$, which was considered to be due to the diffusion of catechin molecules present on the nanoparticle surface. This was followed by a slow and sustained release that was attributed to the flow of the catechin molecules entrapped in the core of the nanoparticle [36]. Hence, a positive correlation was noted between catechin load and sustained release which signified the importance of drug load as a variable in release rate profiles [37]. Further analysis of the release kinetics and mechanism of release of catechin was carried out. The release kinetics CATNP $(10 \mathrm{mg} / \mathrm{ml})$ formulation was in correlation with the Hixson-Crowell model, which mainly applies to pharmaceutical dosage forms and followed Fickian release; that is, the release was through the mode of diffusion [14]. This supports the burst release hypothesis and attests to the fact that the drug burst was not due to nanoparticle degradation or erosion.

Catechin release was also studied under SGF and SIF conditions to better understand the protective role of the PEG coating. Release rate profiles recorded protection of $60 \%$ catechin against the activity of gastrointestinal enzymes. Based on previous literature, we can assume that the addition of PEG to the nanoparticle shell prevented enzyme docking on polymer surface which in turn prevented drug and nanoparticle shell degradation [16]. The need of a protective coating of PEG is further attested by an earlier study on PLA nanoparticles without any protective coating, which showed strong drug degradation in simulated gastric and intestinal fluids. Here only $11 \%$ and $34 \%$ of PLA nanoparticles maintained their integrity in simulated gastric and intestinal fluids, respectively [38].

Antioxidant and metal chelation potentials were studied for free catechin and CATNP in a time-dependent manner to determine their ability to prevent lipid, protein, and DNA oxidation through hydrogen donation [39]. It was noted that CATNP greatly enhanced the radical scavenging activity of free catechin 1.64-, 1.65-, and 1.57-fold for DPPH, lipid peroxidation, and superoxide scavenging assays. Likewise, a 1.51 -fold boost was also noted in the metal chelation rate. This suggested that encapsulation of catechin into PLA/PEG nanoparticles greatly enhanced the stability and antioxidant and metal chelation potential of free catechin.

\section{Conclusion}

Polymer nanoparticles were synthesized to encapsulate a bioactive flavonoid, catechin. Here catechin was encapsulated successfully in a noncrystalline state with an encapsulation efficiency of $96 \%$. Release profiles of catechin from CATNP showed a slow and sustained release suggesting that PLA/PEG nanoparticles were suitable for catechin encapsulation and release in acidic environment, such as the gastric and intestinal systems. These reports can be useful in designing a delivery system for specific compounds in the stomach for treatment of local diseases. A significant increase in the antioxidant and metal chelation potentials of CATNP was also observed. These finding can be useful in designing a delivery system for delaying oxidative stress and improving shelf life of food products. However, further in vitro and in vivo studies are required to better understand the effects of CATNP. Nonetheless, this type of delivery system could be suitable for the encapsulation of bioactive compounds with beneficial properties for human health.

\section{Abbreviations \\ CATNP: Catechin encapsulated polymeric nanoparticles \\ DCM: Dichloromethane \\ DPPH: 2-Thiobarbituric acid, 2,2-diphenyl-1-picrylhydrazyl}

Ferrozine: 3-(2-Pyridyl)-5,6-diphenyl-1,2,4-triazine$\mathrm{p}, \mathrm{p}^{\prime}$-disulfonic acid monosodium salt hydrate

FT-IR: $\quad$ Fourier transform infrared spectroscopy

PBS: $\quad$ Phosphate buffered saline

PEG: $\quad$ Polyethylene glycol

PLA: $\quad$ Poly(D,L-lactic acid)

PVA: Polyvinyl alcohol

SEM: $\quad$ Scanning electron microscope

SGF: $\quad$ Simulated gastric fluid

SIF: $\quad$ Simulated intestinal fluid

XRD: X-ray diffraction.

\section{Conflicts of Interest}

The authors declare that they have no conflicts of interest. 


\section{Authors' Contributions}

Zaved Ahmed Khan and Abul Kalam Azad Mandal designed the experiments. Neha Atulkumar Singh performed the nanoparticle synthesis and characterization and antioxidant and metal chelation activity analysis. Neha Atulkumar Singh, Zaved Ahmed Khan, and Abul Kalam Azad Mandal analyzed the data and wrote the manuscript. All authors have read and approved the final manuscript.

\section{Acknowledgments}

The authors acknowledge the management of VIT University for providing research facilities and financial support in the form of seed money. They would also like to acknowledge the fellowship received by the first author from VIT University.

\section{References}

[1] C. C. Akoh and D. B. Min, Food Lipids: Chemistry, Nutrition, and Biotechnology, CRC Press, 4th edition, 2008.

[2] L. N. Patralekh and G. Mukherjee, "In Vitro Studies on Antioxidant and Iron-chelating Activity of Enhydra fluctuans Lour," Scientific Culture, vol. 76, pp. 537-539, 2010.

[3] T.-H. Wu, F.-L. Yen, L.-T. Lin, T.-R. Tsai, C.-C. Lin, and T.M. Cham, "Preparation, physicochemical characterization, and antioxidant effects of quercetin nanoparticles," International Journal of Pharmaceutics, vol. 346, no. 1-2, pp. 160-168, 2008.

[4] B. N. Ames, M. K. Shigenaga, and T. M. Hagen, "Oxidants, antioxidants, and the degenerative diseases of aging," Proceedings of the National Academy of Sciences of the United States of America, vol. 90, no. 17, pp. 7915-7922, 1993.

[5] O. Weinreb, S. Mandel, T. Amit, and M. B. H. Youdim, "Neurological mechanisms of green tea polyphenols in Alzheimer's and Parkinson's diseases," Journal of Nutritional Biochemistry, vol. 15, no. 9, pp. 506-516, 2004.

[6] R. Singh, N. Akhtar, and T. M. Haqqi, "Green tea polyphenol epigallocatechin-3-gallate: Inflammation and arthritis," Life Sciences, vol. 86, no. 25-26, pp. 907-918, 2010, [corrected].

[7] G. Nie, C. Jin, Y. Cao, S. Shen, and B. Zhao, "Distinct effects of tea catechins on 6-hydroxydopamine-induced apoptosis in PC12 cells," Archives of Biochemistry and Biophysics, vol. 397, no. 1, pp. 84-90, 2002.

[8] H. Pool, D. Quintanar, J. D. D. Figueroa et al., "Antioxidant effects of quercetin and catechin encapsulated into PLGA nanoparticles," Journal of Nanomaterials, vol. 2012, Article ID 145380, 12 pages, 2012.

[9] R. M. Mainardes, N. M. Khalil, and M. P. D. Gremião, "Intranasal delivery of zidovudine by PLA and PLA-PEG blend nanoparticles," International Journal of Pharmaceutics, vol. 395, no. 1-2, pp. 266-271, 2010.

[10] Z. Zhang and S.-S. Feng, "The drug encapsulation efficiency, in vitro drug release, cellular uptake and cytotoxicity of paclitaxelloaded poly(lactide)-tocopheryl polyethylene glycol succinate nanoparticles," Biomaterials, vol. 27, no. 21, pp. 4025-4033, 2006.

[11] M. Karamaæ, A. Kosiñska, and U. D. Chavan, "Rapid chromatographic method for separation of green tea proanthocyanidins," Polish Journal Of Food And Nutrition Sciences, vol. 14, no. 3, pp. 243-247, 2005.
[12] M. Rajan and V. Raj, "Encapsulation, characterisation and invitro release of anti-tuberculosis drug using chitosan - poly ethylene glycol nanoparticles," International Journal of Pharmacy and Pharmaceutical Sciences, vol. 4, no. 4, pp. 255-259, 2012.

[13] B. K. Patel, R. H. Parikh, and P. S. Aboti, "Development of Oral Sustained Release Rifampicin Loaded Chitosan Nanoparticles by Design of Experiment," Journal of Drug Delivery, vol. 2013, Article ID 370938, 10 pages, 2013.

[14] S. Dash, P. N. Murthy, L. Nath, and P. Chowdhury, "Kinetic modeling on drug release from controlled drug delivery systems," Acta Poloniae Pharmaceutica, vol. 67, no. 3, pp. 217-223, 2010.

[15] T. P. Ravi and A. K. Mandal, "Effect of alcohol on release of green tea polyphenols from casein nanoparticles and its mathematical modeling," Research Journal of Biotechnology, vol. 10, no. 8, pp. 99-104, 2015.

[16] D. Das and S. Lin, "Double-coated poly (butylcynanoacrylate) nanoparticulate delivery systems for brain targeting of dalargin via oral administration," Journal of Pharmaceutical Sciences, vol. 94, no. 6, pp. 1343-1353, 2005.

[17] M. N. Alam, N. J. Bristi, and M. Rafiquzzaman, "Review on in vivo and in vitro methods evaluation of antioxidant activity," Saudi Pharmaceutical Journal, vol. 21, no. 2, pp. 143-152, 2013.

[18] E. D. Wills, "Mechanisms of lipid peroxide formation in animal tissues.", Biochemical Journal, vol. 99, no. 3, pp. 667-676, 1966.

[19] J.-L. Song and Y. Gao, "Effects of methanolic extract form Fuzhuan brick-tea on hydrogen peroxide-induced oxidative stress in human intestinal epithelial adenocarcinoma Caco-2 cells," Molecular Medicine Reports, vol. 9, no. 3, pp. 1061-1067, 2014.

[20] A. Kumari, S. K. Yadav, Y. B. Pakade, B. Singh, and S. C. Yadav, "Development of biodegradable nanoparticles for delivery of quercetin," Colloids and Surfaces B: Biointerfaces, vol. 80, no. 2, pp. 184-192, 2010.

[21] M. A. Ebrahimzadeh, S. M. Nabavi, and S. F. Nabavi, "Correlation between the in vitro iron chelating activity and poly phenol and flavonoid contents of some medicinal plants," Pakistan Journal of Biological Sciences, vol. 12, no. 12, pp. 934-938, 2009.

[22] M. F. Zambaux, F. Bonneaux, R. Gref, E. Dellacherie, and C. Vigneron, "Preparation and characterization of protein Cloaded PLA nanoparticles," Journal of Controlled Release, vol. 60, no. 2-3, pp. 179-188, 1999.

[23] J. Xing, D. Zhang, and T. Tan, "Studies on the oridoninloaded poly(D,L-lactic acid) nanoparticles in vitro and in vivo," International Journal of Biological Macromolecules, vol. 40, no. 2, pp. 153-158, 2007.

[24] D. Quintanar-Guerrero, E. Allémann, H. Fessi, and E. Doelker, "Preparation techniques and mechanisms of formation of biodegradable nanoparticles from preformed polymers," Drug Development and Industrial Pharmacy, vol. 24, no. 12, pp. 1113$1128,1998$.

[25] K. Sonaje, J. L. Italia, G. Sharma, V. Bhardwaj, K. Tikoo, and M. N. V. R. Kumar, "Development of biodegradable nanoparticles for oral delivery of ellagic acid and evaluation of their antioxidant efficacy against cyclosporine A-induced nephrotoxicity in rats," Pharmaceutical Research, vol. 24, no. 5, pp. 899-908, 2007.

[26] S. Galindo-Rodriguez, E. Allémann, H. Fessi, and E. Doelker, "Physicochemical parameters associated with nanoparticle formation in the salting-out, emulsification-diffusion, and nanoprecipitation methods," Pharmaceutical Research, vol. 21, no. 8, pp. 1428-1439, 2004. 
[27] V. J. Mohanraj and Y. Chen, "Nanoparticles - a review," Tropical Journal of Pharmaceutical Research, vol. 5, no. 1, pp. 561-573, 2006.

[28] C. E. Astete and C. M. Sabliov, "Synthesis and characterization of PLGA nanoparticles," Journal of Biomaterials Science, Polymer Edition, vol. 17, no. 3, pp. 247-289, 2006.

[29] Y. Zhang, Y. Yang, K. Tang, X. Hu, and G. Zou, "Physicochemical characterization and antioxidant activity of quercetinloaded chitosan nanoparticles," Journal of Applied Polymer Science, vol. 107, no. 2, pp. 891-897, 2008.

[30] M. C. Yue, K. W. Ming, and M. H. Pan, "Catechin transformation as influenced by aluminum," Journal of Agricultural and Food Chemistry, vol. 54, no. 1, pp. 212-218, 2006.

[31] A. J. R. Lasprilla, G. A. R. Martinez, B. H. Lunelli, J. E. J. Figueroa, A. L. Jardini, and R. M. Filho, "Synthesis and characterization of poly (lactic acid) for use in biomedical field," Chemical Engineering Transactions, vol. 24, pp. 985-990, 2011.

[32] M. S. Maoela, O. A. Arotiba, P. G. L. Baker et al., "Electroanalytical determination of catechin flavonoid in ethyl acetate extracts of medicinal plants," International Journal of Electrochemical Science, vol. 4, no. 11, pp. 1497-1510, 2009.

[33] R. Ponnuraj, K. Janakiraman, S. Gopalakrishnan, Senthilnathan K., Meganathan V., and Saravanan P., "Formulation and characterization of epigallocatechin gallate nanoparticles," Indo American Journal of Pharmaceutical Research, vol. 5, no. 1, pp. 387-399, 2015.

[34] T. Govender, T. Riley, T. Ehtezazi et al., "Defining the drug incorporation properties of PLA-PEG nanoparticles," International Journal of Pharmaceutics, vol. 199, no. 1, pp. 95-110, 2000.

[35] J. Panyam, D. William, A. Dash, D. Leslie-Pelecky, and V. Labhasetwar, "Solid-state solubility influences encapsulation and release of hydrophobic drugs from PLGA/PLA nanoparticles," Journal of Pharmaceutical Sciences, vol. 93, no. 7, pp. 1804-1814, 2004.

[36] C. Gómez-Gaete, N. Tsapis, M. Besnard, A. Bochot, and E. Fattal, "Encapsulation of dexamethasone into biodegradable polymeric nanoparticles," International Journal of Pharmaceutics, vol. 331, no. 2, pp. 153-159, 2007.

[37] T. Zhong, Z. Jiang, P. Wang, S. Bie, F. Zhang, and B. Zuo, "Silk fibroin/copolymer composite hydrogels for the controlled and sustained release of hydrophobic/hydrophilic drugs," International Journal of Pharmaceutics, vol. 494, no. 1, article 15118, pp. 264-270, 2015.

[38] M. Tobío, A. Sánchez, A. Vila et al., "The role of PEG on the stability in digestive fluids and in vivo fate of PEGPLA nanoparticles following oral administration," Colloids and Surfaces B: Biointerfaces, vol. 18, no. 3-4, pp. 315-323, 2000.

[39] K. E. Heim, A. R. Tagliaferro, and D. J. Bobilya, "Flavonoid antioxidants: chemistry, metabolism and structure-activity relationships," Journal of Nutritional Biochemistry, vol. 13, no. 10, pp. 572-584, 2002. 

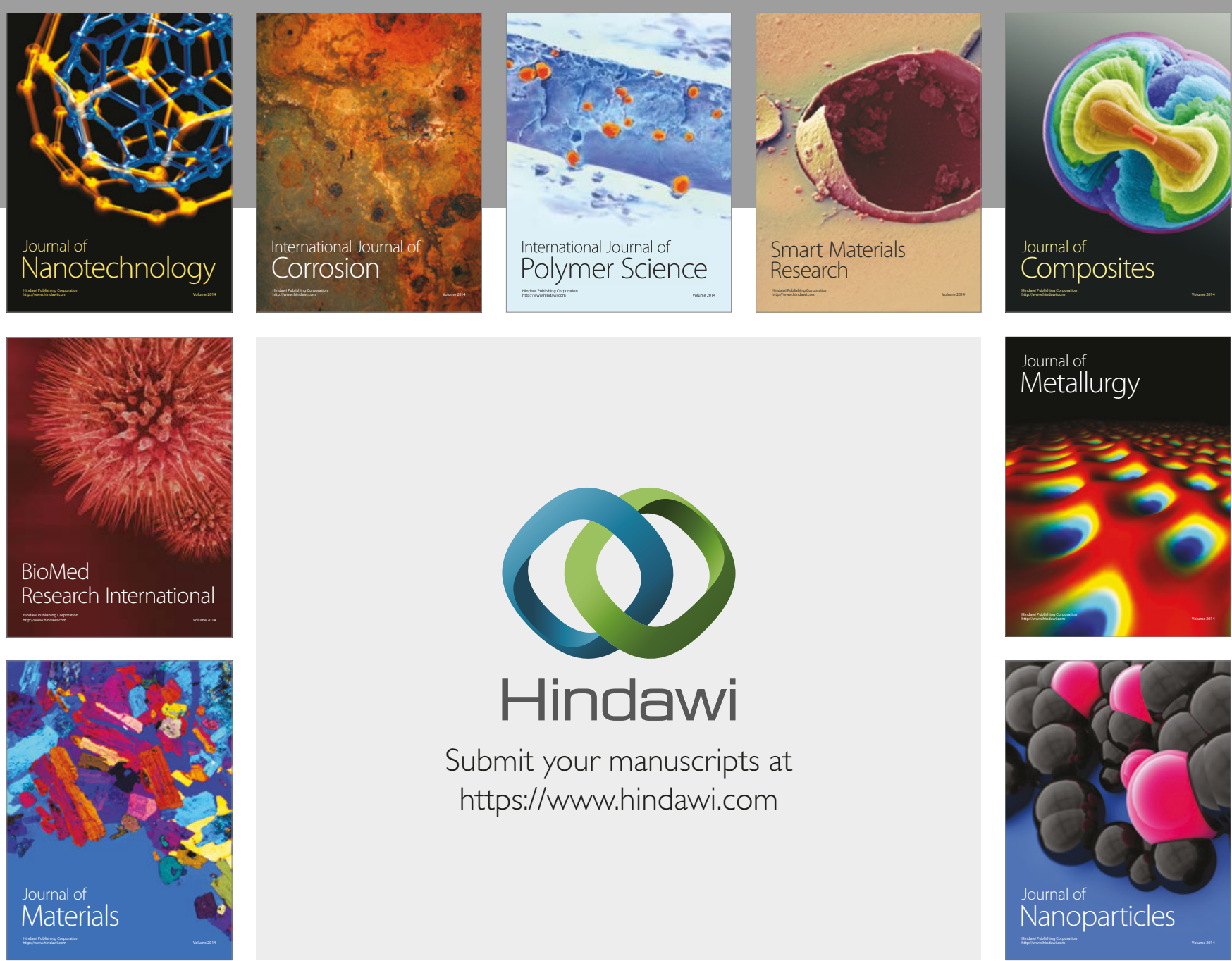

\section{Hindawi}

Submit your manuscripts at

https://www.hindawi.com
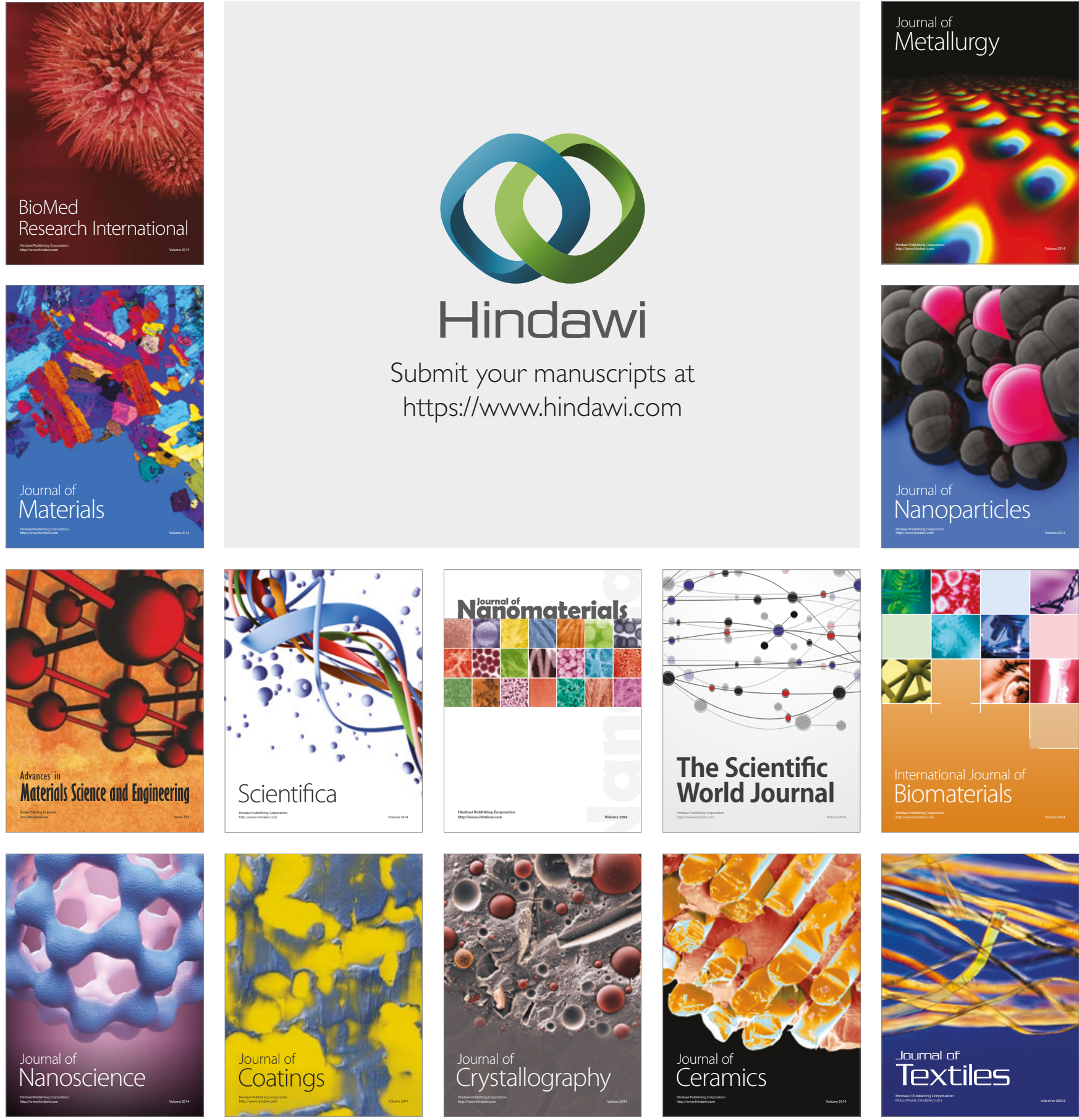

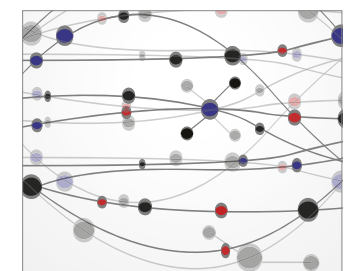

The Scientific World Journal
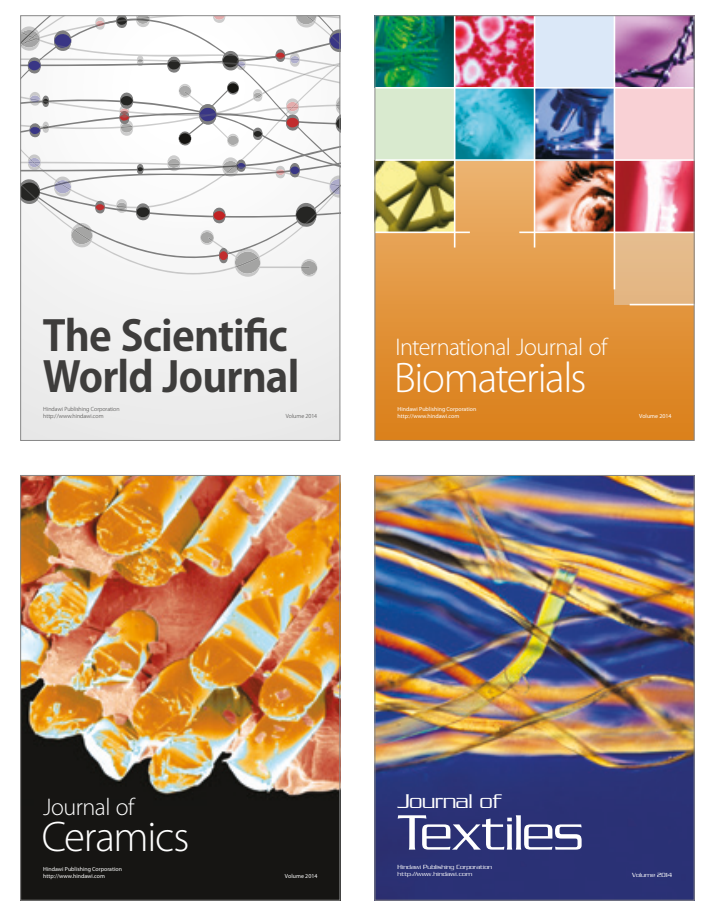